\title{
Apropriação e uso de tecnologias intelectuais: intervenção em uma comunidade popular urbana
}

\author{
Isa Maria Freire \\ isafreire@globo.com \\ Universidade Federal da Paraíba \\ Maria Giovanna Guedes Farias \\ mgiovannaguedes@gmail.com \\ Universidade Federal da Paraíba
}

Resumo: Apresenta reflexão sobre pesquisa de doutorado em andamento, que está sendo realizada no Programa de Pós-Graduação em Ciência da Informação da Universidade Federal da Bahia (PPGCI/UFBA). A fundamentação teórica está alicerçada na mediação da informação, tendo como objetivo desenvolver competência informacional nos moradores da Comunidade objeto de estudo. Essas competências serão implementadas mediante treinamentos em parceria com o Laboratório de Tecnologias Intelectuais - LTi do Departamento de Ciência da Informação juntamente com o Departamento de Informática da Universidade Federal da Paraíba (UFPB) com o PPGCI/UFBA. Adota-se a metodologia da pesquisa-ação, de modo a promover a rede de cooperação necessária como suporte para elaboração de um modelo de mediação, apropriação e uso de tecnologias intelectuais, passível de ser aplicado em outras comunidades. A investigação recorre ao auxílio da observação participante, visando acompanhar a realidade no campo de pesquisa, fazendo uso do diário de campo. O propósito do projeto é construir uma rede de cooperação para transformar realidades e ultrapassar fronteiras, promovendo informação e conhecimento para quem deles necessita.

Palavras-chave: mediação da informação; inclusão social; comunidades; competência informacional.

Abstract: Presents reflections on doctoral research, which is being held at the Postgraduate Program in Information Science at the Federal University of Bahia (PPGCI/UFBA). The theoretical framework is based on the mediation of information, aiming at developing information literacy in the Community residents object of this study. These skills will be implemented through training in partnership with the Laboratory of Intellectual Technologies - LTi from the Department of Information Science and the Computer Science Department of Federal University of Paraíba and the PPGCI/UFBA. Will be adopted the methodology of action research in order to promote cooperation network as necessary to support development of a mediation model, ownership and use of intellectual technologies, which can be applied in other communities. The investigation also employ the help of participant observation, to monitor the reality in the field of research, making use of the field diary. The purpose of the project is to build a cooperative network to transform realities and cross boundaries, promoting information and knowledge to those in need in society

Keywords: mediation of information; social inclusion; communities; information literacy. 


\section{INTRODUÇÃO}

Esse artigo objetiva refletir a respeito do arcabouço teórico e metodológico de pesquisa de doutorado em andamento no Programa de Pós-Graduação em Ciência da Informação na Universidade Federal da Bahia (PPGCI/UFBA). A justificativa para realização desse estudo se fundamenta na necessidade de continuar atuando junto a uma comunidade popular urbana ${ }^{1}$ socialmente desfavorecida, na oportunidade de proporcionar aos moradores da localidade a possiblidade de caminharem no ciberespaço como forma de inclusão na sociedade contemporânea.

A pesquisa se fundamenta nos conceitos da mediação da informação, visando desenvolver competências em tecnologias intelectuais e digitais de informação para inclusão social e promoção da cidadania na Comunidade Santa Clara (CSC), campo de pesquisa, localizado na cidade de João Pessoa, Paraíba. Entende-se que a mediação da informação representa uma oportunidade de atuar junto a comunidades populares urbanas, para ampliar as possibilidades de ação dos sujeitos dessas comunidades no mundo, para serem reconhecidos e se reconhecerem, como uma forma de motivar cada morador a lutar por melhorias para si mesmo e para a coletividade, construindo um mundo melhor no presente e para a posteridade. Pois, como esclarece Almeida Júnior (2008, p. 46) a mediação da informação é "toda ação de interferência - realizada pelo profissional da informação direta ou indireta; consciente ou inconsciente; singular ou plural; individual ou coletiva; que propicia a apropriação de informação que satisfaça, plena ou parcialmente, uma necessidade informacional". Destarte, parafraseando Crippa e Almeida (2011, p. 191), para as Ciências Sociais a noção de mediação está intrinsecamente ligada às chamadas "teorias da ação". Além disso, a mediação da informação proporciona, conforme Varela e Barbosa (2009), a ação que se interpõe entre sujeito e objeto de aprendizagem.

É justamente essa ação de interferência que tenciona-se promover na CSC através das técnicas, instrumentos, suportes, recursos, agentes e processos da mediação da informação e que deixam de ser simples artifícios de transferência de conteúdos informacionais para se constituírem em verdadeiros dispositivos produtores de sentidos. (PERROTTI; PIERUCCINI, 2007).

Toda ação de mediação, de intervenção no regime de informação da Comunidade Santa Clara desta pesquisa, terá como parceiro o Laboratório de Tecnologias Intelectuais - LTi do Departamento de Ciência da Informação da Universidade Federal da Paraíba (DCI/UFPB),

\footnotetext{
${ }^{1}$ Esse estudo visa dá prosseguimento a pesquisa de mestrado realizado no Programa de Pós-Graduação em Ciência da Informação da Universidade Federal da Paraíba tendo como campo de pesquisa a Comunidade Santa Clara.
} 
conduzido por um projeto de pesquisa-ação que tem como objetivo promover ações de mediação da informação para comunidades urbanas, através de treinamento em tecnologias para desenvolvimento de competências informacionais nos moradores dessas comunidades, ao mesmo tempo desenvolver uma reflexão sobre esta experiência de modo a elaborar um modelo para mediação, apropriação e uso de tecnologias intelectuais em outras comunidades. Para a efetivação desta pesquisa, conta-se com a parceria do Departamento de Informática (DI) e do Programa de Pós-Graduação em Ciência da Informação da UFPB. Com essa rede de projetos, objetiva-se transformar realidades e ultrapassar fronteiras, promover informação e conhecimento para aqueles que deles mais necessitam.

\section{REGIME DE INFORMAÇÃO DA COMUNIDADE}

A intervenção a ser promovida no atual regime de informação da Comunidade Santa Clara ocorrerá a partir do regime já identificado e alterado durante pesquisa de mestrado acima citada, e que tem como base modelo proposto por González de Gómez (1999; 2002; 2003; 2004) a partir de Frohmann (1995) definido como:

[...] conjunto mais ou menos estável de redes sociocomunicacionais formais e informais nas quais informações podem ser geradas, organizadas e transferidas de diferentes produtores, através de muitos e diversos meios, canais e organizações, a diferentes destinatários ou receptores, sejam estes usuários específicos ou públicos amplos. [O regime] está configurado, em cada caso, por plexos de relações plurais e diversas: intermediáticas; interorganizacionais e intersociais. [Sendo constituído, assim,] pela figura combinatória de uma relação de forças, definindo uma direção e arranjo de mediações comunicacionais e informacionais dentro de um domínio funcional (saúde, educação, previdência, etc.), territorial (município, região, grupo de países) ou de sua combinação. (GONZÁLEZ DE GÓMEZ, 1999, p.24; 2002, p.34).

Para Delaia (2009) o regime de informação é um caminho para compreender uma política de informação e as relações diretas e indiretas das e entre as comunidades, instituições, organismos do público ao privado, no que diz respeito às ações de informação.

O modelo original de regime da informação proposto por González de Gómez (1999; 2002) é composto por quatro componentes: dispositivos de informação, artefatos de informação, atores sociais e ações de informação. No regime da Comunidade Santa Clara, os artefatos de informação identificados antes e durante a coleta de dados, dos quais os moradores faziam uso para transmissão e recepção de dados foram: a televisão, o rádio, computador, Internet e a comunicação oral. Neste último artefato, a notícia é veiculada por meio de comunicação direta, face a face, e por meio do qual, a presidente da Associação de Moradores faz as informações chegarem de porta a porta, a exemplo do anúncio do programa 
do governo federal de troca de geladeiras velhas por novas. Ela esteve na casa de cada morador explicando como funciona este programa e o prazo para os moradores se inscreverem. As ações de informação identificadas nesse regime se focalizam no registro e na divulgação do tesouro de conhecimentos da CSC, o que há de mais valioso e pulsante na Comunidade.

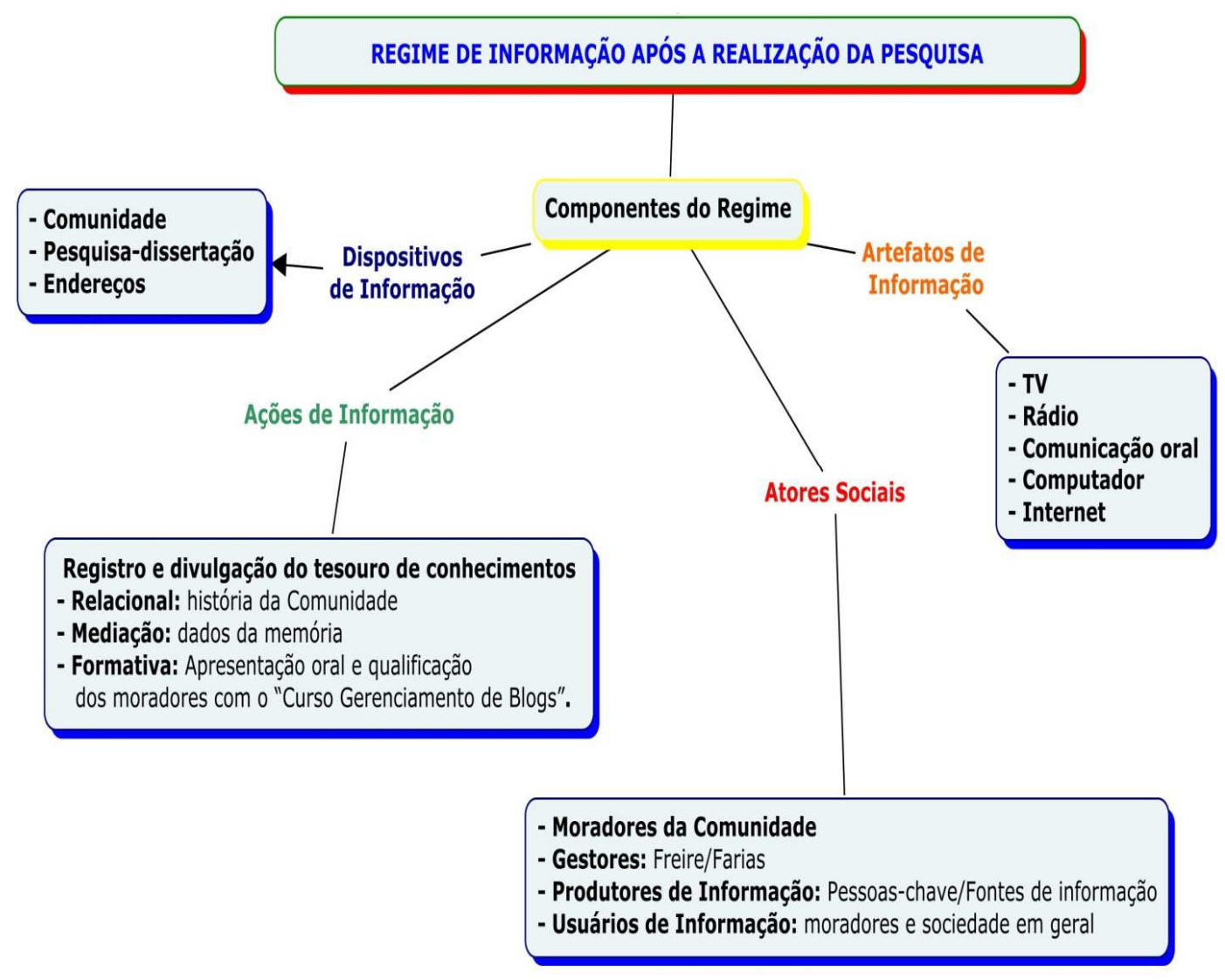

Figura 1: Regime de Informação da CSC

Fonte: Adaptado de GONZÁLEZ DE GÓMEZ (1999) e DELAIA (2009) a partir dos dados da pesquisa.

As ações de informação estão divididas em três categorias: a relacional composta pela história da Comunidade, um fator de ligação entre os moradores mais antigos, que viram a Santa Clara nascer e um atrativo para os jovens interessados em saber da história do espaço onde eles cresceram. A ação de mediação se apoia nos dados da memória de cada morador, que ao expressar esses dados/informações podem transformar o mundo ao seu redor, mudar a realidade onde vivem. Observamos durante a pesquisa de campo, uma das fontes de informação narrando para alguns jovens a forma como os moradores viviam há alguns anos na Comunidade comparando com a realidade atual. No caso da ação formativa, empreitada pela pesquisa, ela ocorreu na forma de apresentação oral de como o estudo se deu, da qualificação 
de três pessoas da Comunidade no "Curso Gerenciamento de Blog", e do resultado do trabalho desenvolvido durante o mestrado.

\section{MEDIAÇÃO DA INFORMAÇÃO}

A mediação da informação permeia todo o tear científico dessa pesquisa, por ser tratada como ação vinculada à vida, ao movimento, ao processo de construção de sentidos (GOMES, 2010). Nas palavras da autora, age-se em relação à realidade tomando como referência o significado que atribuí-se a essa realidade construída nas interações sociais e mediações simbólicas. É por meio da mediação que as expectativas são manifestadas, sustentando as interações sociais.

A hipótese suscitada por Perrotti e Pieruccini (2007, p. 64) de que se mediar é intermediar, seria também ação de aproximar seres considerados como dados independentemente desta ação. O que significa dizer que "[...] a natureza, o modo de ser e de funcionar de tais seres não só estão presentes, como atuam efetivamente nos processos de mediação; da mesma forma, atuam a natureza, o modo de ser e de funcionar dos elementos mediadores". Os autores empregam em seus trabalhos "a mediação cultural como categoria intrínseca aos processos de significação, [...] essencial, condição que leva a considerar os elementos que constituem seus processos não simplesmente como ferramentas, mas como signos, portadores de sentidos [...]" (PERROTTI; PIERUCCINI, 2007, p. 64).

O homem, em contato com o mundo, "[...] lida tanto com objetos de dimensão imediata de percepção, quanto com outros objetos de dimensão mediata, a partir dos quais vai construindo e reconstruindo sua compreensão." (GOMES, 2010, p. 88). Nesse processo, de acordo com autora:

[...] emergem as contradições, que só podem ser elaboradas no debate, na dialogia, enfim, no processo dialético. Logo, os procedimentos sociais transcorrem em contextos de tensões e contradições, considerando-se a natureza dialógica, incompleta, aberta e heterogênea da vida social. Pode-se dizer que a consciência é, ao mesmo tempo, resultado dos processos cognitivo e social, que se desenvolvem na comunicação. A experiência humana se dá graças às práticas comunicativas e simbólicas que constituem o locus da mediação.

Mediação esta que se relaciona, conforme a autora, com a comunicação e caracterizando-se "[...] como um processo de intersubjetividades, resultante da negociação e da disputa de sentidos, que permite aos sujeitos ultrapassar e interpenetrar esses sentidos e gerar novas significações" (GOMES, 2010, p. 88), pois,

No exercício da comunicação, a linguagem dá expressão aos significados, permitindo a materialidade e a imaterialidade da informação. No trabalho 
com a imaterialidade da informação, surgem questões ligadas à diversidade e aos atributos de dispositivos culturais de registro, armazenamento, recuperação, divulgação, acesso e uso da informação, como também ao processo dialógico que permite a um universo distinto de interlocutores espaço de contato e de manifestação da subjetividade que emana da interlocução (inter e intrasubjetiva).

Ainda sobre a imaterialidade da informação, Almeida Júnior (2009, p. 97), afirma que a “[...] mediação da informação permite e exige concepção de informação que desloque o usuário da categoria de mero receptor, colocando-o como ator central do processo de apropriação". O autor defende que o usuário determina a existência ou não da informação, pois ela existe apenas no intervalo entre o contato da pessoa com o suporte e a apropriação da informação, sendo entendida "a partir da modificação, da mudança, da reorganização, da reestruturação, enfim, da transformação do conhecimento" (ALMEIDA JUNIOR, 2009, p. 97). E é esta mudança, transformação do conhecimento, de realidade que tenciona-se alcançar por meio da mediação da informação que "[...] passa a se constituir não como coadjuvante no âmbito da $\mathrm{Cl}$, mas interferindo em seu próprio objeto." (ALMEIDA JÚNIOR, 2009, p. 92). Objeto este que, na visão do autor, deve ser reconsiderado, ou seja, o objeto da $\mathrm{Cl}$ passaria a ser a mediação da informação, e não mais a informação, pois “[...] se todo fazer do profissional da informação é voltado para a mediação - quer implícita, quer explícita - considerarmos a mediação da informação como objeto da área é um encaminhamento lógico e natural". (ALMEIDA JUNIOR, 2009, p. 94-95).

Nesta perspectiva, da mediação como ação vinculada ao processo de construção de sentidos caminha-se junto a Almeida Júnior (2008) com o entendimento sobre a atuação do profissional da informação, que a partir da consciência da interferência, "passa a ser entendido em uma outra esfera, em um outro estrato profissional, o daqueles que fazem história, são sujeitos na sociedade e participam efetivamente da construção do destino da humanidade" (ALMEIDA JÚNIOR, 2008, p. 48). De acordo com pesquisas realizadas pelo autor, "[...] as ações do profissional da informação não são neutras, não são imparciais e resultam sempre em uma interferência" (ALMEIDA JÚNIOR, 2008, p. 48). Desta forma, o que realmente ocorre é mais do que isso, pois:

[...] é com a consciência de quem interfere, de quem se realiza como profissional na relação com o usuário é que a democracia da informação poderá se concretizar, porque a democracia pressupõe lutas e embates entre ideias, concepções, valores, etc. diferentes; lutas e embates por poder; porque a democracia é o espaço em que essas lutas são travadas. Do mesmo modo, lidando com a informação, os espaços informacionais permitem e propiciem essas lutas e embates, transformando-se nos locais aptos à realização, efetivação e concretização da democracia, da inclusão informacional e social. (ALMEIDA JÚNIOR, 2008, p. 48). 
A inclusão para essa pesquisa ocorre, de acordo com Freire (2008), pela oportunidade de promover nos participantes a competência intelectual de refletir sobre seu espaço e papel na sociedade, que todos ajudam a construir. Pois o cidadão incluído na sociedade da informação pode se beneficiar das tecnologias como instrumentos para obter acesso à informação, além de ter a possibilidade de gerar e compartilhar conhecimento.

\title{
4 INCLUSÃO SOCIAL E ACESSO À TECNOLOGIA
}

A inclusão social se apresenta como um conceito e uma prática no campo da Ciência da Informação, que se caracteriza por adotar um olhar epistemológico de pensar o Outro além das necessidades primárias da pessoa. Segundo Freire (2010), essa visão pode significar um novo olhar sobre a prática, os conceitos e tecnologias disponíveis no campo da $\mathrm{Cl}$. Um olhar que contemple verdadeiramente o usuário, e possa se traduzir no desenvolvimento de uma práxis que aproxime das pessoas e grupos, nos quais a informação produzida poderá se manifestar como possibilidade de conhecimento.

A inclusão social nessa pesquisa passa pela inclusão digital/virtual, pois as ações de inclusão mediante acesso a tecnologias digitais devem ser, como ressalta Freire (2004), consideradas relevantes no conjunto de políticas públicas de inclusão social, uma vez que a comunicação da informação representa não somente a circulação de mensagens que contêm conhecimento com determinado valor para a produção de bens e serviços, mas, também, a objetivação das ideias de racionalização e eficiência dominantes na sociedade moderna. Albagli (2006, p. 17) corrobora o pensamento de Freire (2004), ao enfatizar que "os processos e estratégias de desenvolvimento e inclusão social encontram-se hoje indissociáveis das dinâmicas e políticas de informação, conhecimento, aprendizado e inovação." Entretanto,

\begin{abstract}
A promoção da inovação é frequentemente vista como algo desvinculado da promoção do desenvolvimento local e da inclusão social. Contudo, tais objetivos não são excludentes, e tratá-los de forma conjunta para o desenvolvimento de um dado território tende a gerar resultados mais consistentes e de mais longo prazo. Sem o estabelecimento de ambientes propícios à geração, à incorporação e à disseminação de conhecimentos, não se pode garantir a sobrevivência, a manutenção ou o crescimento consistente dos agentes produtivos, nem, muito menos, o desenvolvimento socioeconômico dos ambientes em que se inserem. $O$ desafio é associar tais estratégias à inclusão dos segmentos sociais marginalizados e ao respeito à diversidade cultural. (ALBAGLI, 2006, p. 19).
\end{abstract}

Usar a tecnologia como meio de comunicação para projetar a identidade cultural (FREIRE, 2006b), para se fazer ouvir nas instâncias do poder político é uma forma de inclusão social/digital. Na visão de Crippa e Almeida (2011, p. 191), a revolução digital trouxe e ainda 
traz fortes mudanças socioculturais. A introdução das TICs modifica potencialmente todas as esferas da sociedade, pois elas nos permitem "ver o que não víamos antes, ao mesmo tempo que tornam o processo mais complexo, fazendo crescer as camadas de mediação e envolvendo indivíduos, grupos, instituições". É por isso que, Freire (2010, p. 83), enfatiza que "a democratização do acesso às tecnologias digitais de informação e comunicação deveria ser vista como elemento fundamental nas políticas inclusão social".

Otlet, La Fontaine, Lévy, Goldmann, Mattelart, Castells, Quéau, Wersig e Neveling, Araújo, Freire: os autores aqui citados abordam e reivindicam a inclusão de todos os grupos populacionais do planeta nos benefícios da revolução das tecnologias intelectuais de informação e comunicação. Para eles, como para nós, a democratização do acesso à informação torna-se crucial na luta da humanidade pela conquista de melhorias na qualidade de vida e para construção de laços solidários entre povos e nações. Nesse processo, a nosso ver, os profissionais da informação têm a relevante função social de aproximar as fontes de informação de seus usuários em potencial, na sociedade. (FREIRE, 2005, p. 138).

Concorda-se com Albuquerque e Cabral (2006, p. 10) de que é grande o desafio daqueles que "acreditam e trabalham pela inclusão social, alcançada por diferentes caminhos, inclusive aquele que denominamos inclusão digital, não sendo suficiente apenas a instalação de equipamentos de informática nas comunidades". O empoderamento real das TICs pode se tornar um verdadeiro "instrumento para as necessárias transformações na realidade social na vida das comunidades." Principalmente se pensarmos na informação como um bem, assim como o alimento, como explicam Kobashi e Tálamo (2003, p. 9), "do mesmo modo que a carência de alimento provoca a fome, a carência da informação provoca a ausência do conhecimento". A informação tecnológica, que na sociedade contemporânea, de acordo com as autoras, assume papel fundamental:

[...] não só por constituir-se crescentemente como direito elementar, mas também porque encontra-se integrado à base da ação na esfera privada ou pública. Parece que, especificamente, o acesso à informação impõe-se como direito global e globalizante em relação aos demais. (KOBASHI; TÁLAMO, 2003, p. 8).

Mark Warschauer em seu livro "Tecnologia e inclusão social: a exclusão digital em debate", publicado em 2006, traz um panorama da inclusão e exclusão social em diversos países baseado em pesquisas de cunho etnográfico e estudo de caso, inclusive no Brasil e trata do letramento como o desenvolvimento de competências para a utilização "proveitosa" das TIC e assim pode-se participar plenamente da sociedade, levando em consideração diversos fatores relacionados a recursos econômicos, emprego, saúde, educação, moradia, lazer, cultura e engajamento cívico. 
Para o autor, o conceito associado ao letramento proporciona a criação de um modelo, "pois o letramento, como o acesso às TIC, inclui uma combinação de equipamentos, conteúdo, habilidades, entendimento e apoio social, a fim de que o usuário possa envolver-se em práticas sociais significativas" (WARSCHAUER, 2006, p. 64). Conforme a autor há várias semelhanças entre o letramento e o acesso à TIC.

\begin{abstract}
Em primeiro lugar, tanto o primeiro quanto o segundo estão intimamente ligados aos avanços da comunicação humana e aos meios de produção do conhecimento. Em segundo lugar, assim como o acesso à TIC é pré-requisito para a plena participação no estágio informacional do capitalismo, o letramento era (e continua sendo) pré-requisito para a plena participação nos primeiros estágios do capitalismo. Em terceiro lugar, tanto o letramento quando o acesso à TIC precisam de conexão a um artefato físico (um livro ou um computador), a fontes de informação (que se expressam como conteúdo dentro desse artefato físico ou por meio dele) e a um nível adequado de habilidade para processar e utilizar essa informação. Em quarto lugar, ambos envolvem não apenas a recepção de informação, mas também a sua produção. Finalmente, ambos estão vinculados a noções algo controversas das exclusões existentes na sociedade: a grande exclusão associada ao letramento e a exclusão digital. (WARSCHAUER, 2006, p. 64-65).
\end{abstract}

Ainda na perspectiva do autor, o acesso à TIC para a promoção da inclusão social não pode está baseado somente no suprimento de equipamentos ou conectividade. Warschauer (2006, p. 75) indica que deve "envolver uma série de recursos, todos desenvolvidos e fomentados com a intenção de acentuar os poderes social, econômico e político dos usuários e das comunidades visados". Para ele, tentar categorizar esses recursos seria arbitrário. No entanto, o autor fez uma análise com base em quatro categorias genéricas que serve aos propósitos tanto de análise como de formulação de políticas. "Essas categorias surgiram da minha pesquisa etnográfica no Havaí e no Egito, assim como das minhas pesquisas de estudos de caso na Califórnia, no Brasil e na Índia" (WARSCHAUER, 2006, p. 75). De acordo com ele, foram identificadas "em termos similares por outros pesquisadores e teóricos, que analisaram questões de tecnologia e inclusão social em diversos contextos". Warschauer (2006, p. 76) explica o modelo, ou seja, os quatro conjuntos de recursos, ressaltando sua relação interativa com o uso da TIC, quais sejam:

a) recursos físicos incluem o acesso a computadores e a conexões de telecomunicação;

b) os recursos digitais referem-se ao material digital, tornado disponível online;

c) os recursos humanos dizem respeito a questões como letramento e educação (incluindo os tipos específicos de práticas de letramento, necessárias para o emprego da informática e para a comunicação online);

d) os recursos sociais têm relação com as estruturas comunitária, institucional e da sociedade que apoiam o acesso à tic. 
Corrobora-se com o autor, quando ele afirma que a presença desses recursos ajuda a assegurar que a TIC possa ser bem usada e explorada, isto é, "por meio da boa utilização da TIC, podemos ajudar a ampliar e fomentar esses recursos", que podem fomentar um círculo virtuoso promovendo o desenvolvimento e a inclusão social. "Se insuficientemente manejados, esses elementos podem fazer parte de um círculo vicioso de subdesenvolvimento e exclusão". (WARSCHAUER, 2006, p. 77). Desta forma, entende-se que a adequada utilização deste conjunto de recursos, no campo de pesquisa, poderá promover a inclusão social dos moradores da Comunidade Santa Clara desenvolvendo a competência informacional de cada um e do grupo.

\section{COMPETÊNCIA INFORMACIONAL: CONCEITOS E PERSPECTIVAS NA PESQUISA}

Essa pesquisa esta ancorada na responsabilidade social em propiciar aos moradores de uma comunidade popular urbana a competência informacional em gerar conhecimento com vistas a sair do estado latente de exclusão social. Para isso, organiza-se uma estrutura de informação visando à interação dos indivíduos com as possibilidades de promoção da cidadania, será mais do que acessar e usar a informação disponível no ciberespaço, o objetivo é promover a mudança no estado cognitivo destas pessoas, incentivando-os a se tornarem independentes futuramente na aquisição do conhecimento que necessitam. Nesta tarefa, o profissional da informação tem o papel de mediador visando colocar em prática o conceito de competência informacional de Dudziak (2003, p. 30), que define-a "pesquisa, estudo e aplicação de técnicas e procedimentos ligados ao processamento e distribuição de informações com base no desenvolvimento de habilidades no uso de ferramentas e suportes tecnológicos". Competência informacional é a tradução da expressão information literacy utilizada por alguns teóricos da Ciência da Informação, mas há também outras denominações para esse termo.

Dudziak (2003, p. 28) analisou a evolução do conceito e, segundo a autora, "pode-se defini-la como o processo contínuo de internalização de fundamentos conceituais, atitudinais e de habilidades necessário à compreensão e interação permanente com o universo informacional e sua dinâmica, de modo a proporcionar um aprendizado ao longo da vida". A American Library Association (ALA, 1989, p. 1) em seu "Report of the Presidential Comittee on information literacy: Final report" traz a definição de competência em informação:

Para ser competente em informação a pessoa deve ser capaz de reconhecer quando precisa de informação e possuir habilidade para localizar, avaliar e usar efetivamente a informação. Para produzir esse tipo de cidadania é 
necessário que escolas e faculdades compreendam o conceito de competência informacional e o integrem em seus programas de ensino e que desempenhem um papel de liderança preparando indivíduos e instituições para aproveitarem as oportunidades inerentes à sociedade da informação. Em última análise, pessoas que têm competência informacional são aquelas que aprenderam a aprender. Essas pessoas sabem como aprender porque sabem como a informação está organizada, como encontrar informação e como usar informação, de tal forma que outros possam aprender com elas.

Essa competência é composta, segundo Feres e Belluzzo (2009, p. 78), de duas dimensões distintas: "um domínio de saberes e habilidades de diversas naturezas que permite a intervenção prática na realidade; e uma visão crítica do alcance das ações e o compromisso com as necessidades mais concretas que emergem e caracterizam o atual contexto social". Eles apresentam diferentes concepções da competência informacional resumindo-as em:

Digital - concepção com ênfase na tecnologia da informação e da comunicação; Informação Propriamente Dita - concepção com ênfase nos Processos Cognitivos e no Social - concepção com ênfase na inclusão social, consistindo em uma visão integrada de aprendizagem ao longo da vida e exercício de cidadania. (FERES; BELLUZZO, 2009, p. 79, grifo dos autores).

Os autores explicam que essa ênfase direciona-se para o exercício da cidadania, para o ser social, "onde o emissor/receptor do fluxo de informação é considerado como um ser inserido em uma dimensão social e ecológica de aprendiz, na busca de uma identidade pessoal e autônoma a partir de sua ação enquanto transformador social". (FERES; BELLUZZO, 2009, p. 82).

Já Dudziak (2005, p. 1), observa que a competência é mais do que uma soma de atributos, "é um processo que se renova constantemente e implica na mobilização adequada de conteúdos interligados, quais sejam, conhecimentos, habilidades e atitudes". Dudziak (2003, p. 30) afirma que muitos pesquisadores relacionam a competência em informação aos processos de busca da informação para construção de conhecimento, envolvendo uso, interpretação e busca de significados, procura-se a construção de modelos mentais, não apenas respostas às perguntas. "O foco está no indivíduo, em seus processos de compreensão da informação e seu uso em situações particulares".

\section{PERCURSO METODOLÓGICO}

Para alcançar os objetivos desse estudo utiliza-se como aporte a pesquisa-ação, por permitir a aproximação da pesquisadora no campo empírico, e por propiciar que a pesquisa e a ação possam estar reunidas em um mesmo processo, o que na visão de Franco (2005, p. 496), reafirma a questão da pesquisa com ação, que vai aos poucos sendo também ação com 
pesquisa. "No desenvolver da pesquisa-ação, há a ênfase na flexibilidade, nos ajustes progressivos aos acontecimentos, fortalecendo a questão da pesquisa com ação."

Além disso, com base nas reflexões de Lima (2007, p. 63), entende-se que a pesquisaação aplicada à pesquisa em Ciência da Informação forma uma combinação interessante, principalmente para essa pesquisa de doutorado, pois proporciona: "[...] de um lado, resultados práticos alcançados pela resolução inovadora de um problema, e, do outro, a contribuição para a ciência em termos de resultados de pesquisa que já foram aplicados e testados no mundo real."

De acordo com Melo Neto (2005), a pesquisa-ação estimula a participação das pessoas envolvidas na pesquisa e abre o seu universo de respostas e passa pelas condições de trabalho e vida da comunidade. Já para Thiollent (1997, p. 15), a pesquisa-ação "consiste essencialmente em acoplar pesquisa e ação em um processo, no qual os atores implicados participam, junto com os pesquisadores, para chegarem interativamente a elucidar a realidade em que estão inseridos." Nessa perspectiva, "ator" seria qualquer grupo de pessoas dispondo de certa capacidade de ação coletiva consciente em um contexto social delimitado, ao poder designar tanto os grupos informantes no meio de uma organização quanto os grupos formalmente constituídos, e "participação" é encarada como propriedade emergente do processo e não como a priori. (FREIRE, 2006a, p. 65).

Um esquema representacional foi desenvolvido por Tripp (2005, p. 446) para mostrar o ciclo básico da investigação-ação dividido em quatro fases. $O$ autor explica que a pesquisaação é um dos inúmeros tipos de investigação-ação, "[...] um termo genérico para qualquer processo que siga um ciclo no qual se aprimora a prática pela oscilação sistemática entre agir no campo da prática e investigar a respeito dela." O processo começa pela investigação passando pela ação, e retornando a investigação da ação aplicada para outra possível ação. Nesse processo, é preciso planejar, implantar o planejado, descrever e avaliar os resultados da ação para melhorar a prática, "[...] aprendendo mais, no correr do processo, tanto a respeito da prática quanto da própria investigação."

De acordo com Franco (2005) durante uma pesquisa-ação é relevante que haja tempo e espaço para que cada sujeito vá se apropriando das mudanças que se operam em suas significações de mundo, que implicam essencialmente mudanças em sua perspectiva como sujeito. Segundo autor,

É preciso tempo para construir a intimidade e um universo cognitivo mais próximo; para barreiras e resistências serem transformadas; para apreensão de novos fatos e valores que emergem de constantes situações de exercício do novo; para reconsiderações de seus papéis profissionais e elaboração das rupturas que emergem, para o imprevisto e o recomeço. (FRANCO, 2005, p. 493). 
Nessa pesquisa, a investigação ocorre com auxílio da observação participante visando acompanhar a realidade no campo de pesquisa, fazendo uso do diário de campo. Ao coletar os dados, registrá-los coletivamente, discuti-los e contextualizá-los, caminharemos, segundo Franco (2005, p. 499), para a construção de saberes e para seu compartilhamento, num processo único, dialético, transformador dos participantes e das condições existenciais. "Um processo que deve produzir transformações de sentido, ressignificações ao que fazemos ou pensamos."

Serão criadas categorias de análises para confrontar com a realidade da Comunidade Santa Clara no intuito de desenvolver o modelo de mediação da informação a ser implantado, testado e analisado com verificação constante do impacto deste modelo no processo de inclusão da CSC na sociedade da informação.

\section{CONSIDERAÇÕES FINAIS}

Transformar realidades e ultrapassar fronteiras, promover informação e conhecimento para aqueles que deles mais necessitam, se tornou a maior inspiração dessa pesquisa, pois ao pensar na responsabilidade social perante o objeto pesquisado, aspira-se, corroborando com Farias e Freire (2011), que os conhecimentos transmitidos pelo trabalho sejam disseminados e que venham a trazer benefícios, neste caso, para a Comunidade Santa Clara, bem como para outras comunidades por meio do modelo para mediação, apropriação e uso de tecnologias intelectuais que será criado.

Quando o cidadão se envolve e se engaja visando discutir questões ou problemas de seu interesse e do interesse da comunidade, os problemas podem ter outras dimensões com facilidade para solução. Como indica Tavares (2011, p. 17), a partir do acesso e uso da informação por meio das TICs, e do desenvolvimento de competências informacionais, o cidadão torna-se capaz de tomar decisões, solucionar problemas, entender melhor a realidade e atuar ativa e criticamente na comunidade.

Isso deve ocorrer para incentivar o engajamento, envolvimento e participação dos membros da comunidade, fazendo com que cada morador se sinta capaz de identificar as informações de que precisa, de acessar e usar criticamente essas informações, de analisar situações e de propor soluções (TAVARES, 2011). Nesta perspectiva, reflete-se que a tecnologia deve ir além de trazer benefícios para quem a conhece. Ela deve, como enfatiza Guerreiro (2006), resultar da observação sobre as necessidades coletivas, traduzidas pelo conjunto de ferramentas desenvolvidas e inventadas com fins práticos para solucionar um determinado problema de ordem social. 
Na Santa Clara, a reorientação ocorreria no sentido de dotar a Comunidade de registro dos conhecimentos adquiridos por pessoas relevantes para essa localidade, que armazenado em um sistema informatizado, pode promover a divulgação dos saberes da CSC de forma inovadora, ao compor um acervo de memória coletiva mediado por profissional da informação. Nesse cenário de transformações reais, como explica Freire (2010, p. 128), cresce a responsabilidade social destes profissionais, seja como produtores de conhecimento no campo científico ou "como facilitadores na comunicação da informação para usuários que dela necessitem, na sociedade, independentemente dos espaços sociais onde vivem e dos papéis que desempenham no sistema produtivo". Usar a tecnologia como meio de comunicação, para projetar a identidade cultural (FREIRE, 2006b), para se fazer ouvir nas instâncias do poder político é uma forma de inclusão social/digital. Segundo a autora, é por isso que a democratização do acesso às tecnologias digitais de informação e comunicação deveria ser vista como elemento fundamental nas políticas inclusão social.

\section{Referências}

ALBAGLI, S. Conhecimento, Inclusão Social e Desenvolvimento Local. Inclusão social, Brasília, v. 1 n. 2, p. 17-22, abr./set. 2006. Disponível em: <http://www.ibict.br/revistainclusaosocial/viewissue.php?id=2>. Acesso em: maio 2011.

ALbuquerque, H. H. F. S. de; CABRAL, A. M. R. Inclusão Digital para a Redução de Desigualdades Sociais: a apropriação e o uso das tecnologias da informação para a atuação cidadã. In: ENCONTRO NACIONAL DE PESQUISA DA ANCIB - ENANCIB, 7., 2006, Marília. Anais... Belo Horizonte: ANCIB, 2006. Disponível em: <http://portalppgci.marilia.unesp.br/enancib/aprovados.php>. Acesso em: maio 2011.

ALMEIDA JÚNIOR, O. F. de. Mediação da informação: ampliando o conceito de disseminação. In: VALENTIM, M. (Org.). Gestão da Informação e do Conhecimento. São Paulo: Editora Polis, 2008 , v. 1, p. 41-54.

AMERICAN LIBRARY ASSOCIATION. Report of the presidential comittee on information literacy: Final report. 10/01/1989. Disponível em: <http://www.ala.org/acrl/nili/ilit1st.html>. Acesso em: 10 nov. 2007.

CRIPPA, G.; ALMEIDA, M. A. Mediação cultural, informação e ensino. ETD: Educação Temática Digital, v. 13, p. 189-206, 2011.

DELAIA, C. R. Subsídios para uma política de gestão da informação da Embrapa Solos - à luz do regime de informação. In: Encontro Nacional de Pesquisa da ANCIB, 2009, João Pessoa. X Enancib. João Pessoa: UFPB-DCI, 2009. (Comunicação oral).

DUDZIAK, Elisabeth Adriana. Competência em Informação: melhores práticas educacionais voltadas para a Information Literacy. In: CONGRESSO BRASILEIRO DE BIBLIOTECONOMIA, 
DOCUMENTAÇÃO E CIÊNCIA DA INFORMAÇÃO, 21, jul. 2005, Curitiba, PR. Anais... Curitiba: FEBAB, 2005. 1 CD-ROM.

. Information literacy: princípios, filosofia e prática. Ciência da Informação. Brasília, v.

32, n. 1, p. 23-35, jan./ abr. 2003. Disponível em: http://www.scielo.br/scielo.php?pid=S010019652003000100003\&script=sci abstract\&tlng=pt. Acesso em: 10 abril 2012.

FARIAS, M. G. G.; FREIRE, I. M. A inclusão da comunidade Santa Clara na sociedade da informação. 2011. 119 f. Dissertação (Mestrado em Ciência da Informação) - Centro de Ciências Sociais Aplicadas, Universidade Federal da Paraíba, João Pessoa, 2011.

FERES, G. G.; BELLUZZO, R. C. B. Competência em informação: um diferencial da qualidade em publicações científicas. Revista Brasileira de Biblioteconomia e Documentação, Nova Série, São Paulo, v.5, n.1/2, p. 70-83, jan./dez. 2009.

FRANCO, M. A. S. Pedagogia da pesquisa-ação. Educação e Pesquisa, São Paulo, v. 31, n.3, p. 483-502, set./dez., 2005.

FREIRE, I. M. A consciência possível para uma ética da informação na sociedade em rede. In: SIMPÓSIO BRASILEIRO DE ÉTICA DA INFORMAÇÃO, 1., 2010, João Pessoa. E-book... João Pessoa: UFPB/DCl, 2010. p. 78-105.

. Janelas da cultura local: abrindo oportunidades para inclusão digital de comunidades.

Ciência da Informação, Brasília, v. 35, n. 3, p. p. 227-235, set./dez. 2006 a.

Construção participativa de instrumento de política pública para gestão e acesso à informação. Perspectivas em Ciência da Informação, v.13, n. 3, p. 195-207, set./dez. 2008.

- Acesso à informação e identidade cultural: entre o global e o local. Ciência da Informação, Brasília, v. 35, n. 2, p. 58-67, maio/ago. 2006b.

. A utopia planetária de Pierre Lévy: uma leitura hipertextual d'a inteligência coletiva. Perspect. Ciênc. Inf., Belo Horizonte, v.10 n.2, p. 132-139, jul./dez. 2005.

. O desafio da inclusão digital. Transinformação. Campinas, v.16, n.2, p.189-194, 2004.

GOMES, H. F. Tendências de pesquisa sobre mediação, circulação e apropriação da informação no Brasil: estudo em periódicos e anais dos ENANCIB (2008-2009). Pesquisa Brasileira em Ciência da Informação, Brasília, v.3, n.1, p.85-99, jan./dez. 2010.

GONZÁleZ DE GÓMEZ, M. N. Novos Cenários Políticos para a informação. Ciência da Informação, Brasília, v. 31, n. 1, p. 27-40, 2002.

Da política de informação ao papel da informação na política contemporânea. Revista Internacional de Estudos Políticos, v. 1, n. 1, p. 57-93, abr. 1999.

GUERREIRO, E. P. Cidade digital: infoinclusão social e tecnológica em rede. São Paulo: SENAC, 2006. 
KOBASHI, Nair Yumiko; TÁLAMO, Maria de Fátima Gonçalves Moreira. Informação, fenômeno e objeto de estudo da sociedade contemporânea. Transinformação, Campinas, 15 (edição especial): 7-21, set./dez., 2003.

LIMA, J. A. O. de. Pesquisa-ação em Ciência da Informação. In: MUELLER, S. P. M. (Org.). Métodos para pesquisa em Ciência da Informação. Brasília: Thesaurus, 2007. p. 63-82. (Série Ciência da Informação e da Comunicação).

MELO NETO, J. F. de. Pesquisa-ação: aspectos práticos da pesquisa-ação nos movimentos sociais populares e em extensão popular. [2005?] Disponível em: <http://www.prac.ufpb.br/copac/extelar/producao_academica/artigos/pa_a_pesquisa_acao.p df>. Acesso em: maio 2011.

PERROTTI, E.; PIERUCCINI, I. Infoeducação: saberes e fazeres da contemporaneidade. In: LARA, M. L. G. de; FUJINO, A.; NORONHA, D. P. (Org.). Informação e contemporaneidade: $\begin{array}{lllll}\text { perspectivas. } & \text { Recife: } & \text { Néctar, } & \text { 47-96. }\end{array}$

TAVARES, R. B. Comunicação da informação em comunidades que leva em conta letramento informacional e trabalho colaborativo para desenvolvimento de cidadania. 2011. 264f. Tese. (Doutorado em Ciência da Informação) - Faculdade de Ciência da Informação - Universidade de Brasília, 2011.

THIOLLENT, M. Pesquisa-ação nas organizações. São Paulo: Atlas, 1997.

TRIPP, D. Pesquisa-ação: uma introdução metodológica. Educação e Pesquisa, São Paulo, v. 31, n. 3, p. 443-466, set./dez., 2005.

VARELA, A.V.; BARBOSA, M, A. Acesso ao conhecimento, mediação e multirreferencialidade. Perspectivas em Ciência da Informação, v. 14, p. 187-203, 2009.

WARSCHAUER, M. Tecnologia e inclusão social: a exclusão em debate. São Paulo: Editora Senac São Paulo, 2006. 